\title{
Enhanced osteogenic commitment of murine mesenchymal stem cells on graphene oxide substrate
}

\author{
Jiyong Kim ${ }^{1 \dagger}$, Hwan D. Kim", Jungha Park, Eun-seo Lee', Eugene Kim, Seunghun S. Lee², Jin-Kyung Yang ${ }^{1}$, \\ Yoon-Sik Lee ${ }^{1}$ and Nathaniel S. Hwang ${ }^{1,2,3^{*}}$
}

\begin{abstract}
Background: Tissue engineering is an interdisciplinary field that attempts to restore or regenerate tissues and organs through biomimetic fabrication of scaffolds with specific functionality. In recent years, graphene oxide (GO) is considered as promising biomaterial due to its nontoxicity, high dispersity, and hydrophilic interaction, and these characteristics are key to stimulating the interactions between substrates and cells.

Method: In this study, GO substrates were fabricated via chemically immobilizing GO at $1.0 \mathrm{mg} / \mathrm{ml}$ on glass slides. Furthermore, we examined the osteogenic responses of murine mesenchymal-like stem cells, C3H10T1/2 cells, on GO substrates.

Results: C3H10T1/2 cells on GO substrates resulted in increased cell surface area, enhanced cellular adhesions, and instigated osteogenic differentiation. Furthermore, priming of $\mathrm{C} 3 \mathrm{H} 10 \mathrm{~T} 1 / 2$ cells with chondrocyte-conditioned medium (CM) could further induce a synergistic effect of osteogenesis on GO substrates.
\end{abstract}

Conclusions: All of these data suggest that GO substrate along with $\mathrm{CM}$ is suitable for upregulating osteogenic responses of mesenchymal stem cells.

Keywords: Graphene, Osteogenesis, Mesenchymal stem cells, Graphene oxide

\section{Background}

Tissue engineering aims to provide biological living substitutes for damaged tissues or organs from accidents, traumas or diseases [1-4]. As a key component for tissue engineering, stem cells are currently being actively utilized in tissue engineering and regenerative materials field. There have been great improvements for differentiating stem cells, in particular, mesenchymal stem cells, to induce tissue-specific differentiation. However, conventional methods may require several weeks to months of cell culture times for intended cell lineage differentiation [5]. Therefore, effective and facile methods for

\footnotetext{
* Correspondence: nshwang@snu.ac.kr

${ }^{\dagger}$ Equal contributors

${ }^{1}$ School of Chemical and Biological Engineering, Institute of Chemical

Processes, Seoul National University, 1 Gwanak-ro, Gwanak-gu, Seoul 151-742,

Republic of Korea

${ }^{2}$ Interdisciplinary Program in Bioengineering, Seoul National University, Seoul

152-742, Republic of Korea

Full list of author information is available at the end of the article
}

stem cell differentiation are greatly needed [6]. Recently, modification of biomaterials surface to induce various cellular responses have been investigated [7-10]. These engineered biomaterials can elicit proliferation and differentiation control by selectively interacting with stem cells $[11,12]$. Furthermore, it is reported that surface interactions caused by nanotopographies and patterned arrays of coated substrates also have significant effects on differentiation of stem cells [12-14]. As a result, developments of new biomaterial would influence stem cell's differentiation pathway and its therapeutic application with soluble proteins such as growth factors.

Due to its hydrophilic functional groups and pibond electrons on its surface [15], graphene oxide (GO) has been intensively researched for tissue engineering and its applications [16]. Its high electrical conductivity, flexibility, and one-atom-thick layer formation allow GO to be highly capable of interacting with cells, growth factors, and hydrophilic substrate 
$[17,18]$. These properties are attributed to not only functional groups such as carbonyl (CO), carboxyl $(-\mathrm{COOH})$ and hydroxyl $(-\mathrm{OH})$ groups but also pibond conjugation by sp2 hybridization. Mesenchymal stem cells cultured on GO-coated surface were reported to exhibit upregulated osteogenic differentiation [19-21]. Mesenchymal stem cells on GO-coated slide showed the increased expression of osteogenic markers, such as osteocalcin $(O C N)$, but downregulated other markers such as $C D 44$, desmin, and MAP2 [21]. In addition, Nayak et al., has reported that the cells on GO substrate exhibited enhanced adhesion and proliferation [21]. As a result, calcium deposition level and alkaline phosphatase expression were raised. This suggests that GO can be used for osteogenic stimulation of mesenchymal stem cells; it is expected to be an outstanding material as a substrate in the application of not only tissue engineering but also dentistry field for advanced implant and clinical tests.

While it is important to understand the characteristics of GO, it should also consider understanding the background of stem cells and their properties. Stem cells are affected by manipulating material-like mechanics and applying growth factor inducers $[22,23]$. Especially during the endochondral ossification process, cartilage is presented by continuous cell division of chondrocytes, which affects the formation of bone tissue. With this phenomenon, Gerstenfeld et al. suggested that substances that are secreted from chondrocyte promote osteogenesis [24]. Moreover, our group also demonstrated that C3H10T1/2 cells primed by bovine chondrocyte-conditioned medium (CM) improved osteogenic responses like expressions of osteogenic gene marker like osteocalcin $(O C N)$, alkaline phosphatase $(A L P)$, collagen type $1(C O L 1)$, and Runt-related transcription factor 2 (Runx2). In addition to the previous osteogenic gene markers, these primed C3H10T1/2 cells indicated calcium deposition when it is cultured with osteogenic factors like dexamethasone and ascorbic acid 2-phosphate (A2P) included osteogenic medium. During in vivo test, as a result, bone regeneration rate of critical defect on the mouse calvaria was increased [25].

Based on our previous studies, we hypothesized that GO could bring synergistic effects to C3H10T1/2 cells by priming with $\mathrm{CM}$, complemented with bovine chondrocyte secreted factors. With the characteristics of GO substrate previously stated, chondrocyte secreted factors can have an enhanced influence on stem cell differentiation, leading to up-regulated osteogenesis. These synergistic effects are anticipated to have a significant influence on the osteogenic differentiation experiments in the aspect of improved differentiation induction to the osteogenesis.

\section{Methods}

\section{Cell priming with conditioned medium}

Full-thickness articular cartilage was harvested from the patellofemoral groove and distal femoral condyle of bovine legs as previously described [26]. Collected cartilage tissues were cut into small pieces and incubated with $0.2 \%$ type II collagenase (Worthington Biochemical, USA) solution at $37{ }^{\circ} \mathrm{C}$ for $16 \mathrm{~h}$. Isolated chondrocytes were filtered with $40 \mu \mathrm{m}$ mesh and washed with phosphate buffered saline (PBS). To make a conditioned medium, primary bovine chondrocytes were cultured with serum-free medium (15 ml DMEM including 1\% Pen Strep) on culture plates (150 mm diameter) for $24 \mathrm{~h}$. The chondrocyte-cultured serum-free medium was then filtered with a $0.2 \mu \mathrm{m}$ syringe filter and supplemented with 10\% FBS (Gibco, USA) to make CM. In order to make a primed cell, C3H10T1/2 cells were cultured with $\mathrm{CM}$ for 14 days.

\section{Graphene oxide (GO) substrate film preparation}

Graphite flake and potassium permanganate $\left(\mathrm{KMnO}_{4}\right)$ were purchased from Sigma Aldrich (St. Louis, MO, USA). Sodium nitrate was obtained from Shimakyu's pure chemical (Osaka, Japan). Sodium hydroxide and sulfuric acid were purchased from Dae-Jung Chemicals (Korea). (GO) was synthesized from graphite flakes by modified Hummers method as previously described [27]. Graphite was oxidized in $\mathrm{H}_{2} \mathrm{SO}_{4}$ and $\mathrm{KMnO}_{4}$, then, sonicated for $1.5 \mathrm{~h}$ at $12 \mathrm{~W}$ in an ice-bath. Subsequently centrifuged and GO was resuspended with $\mathrm{H}_{2} \mathrm{O}$ intensively. Cover glass $(1.5 \times 1.5 \mathrm{~cm})$ were treated with piranha solution $\left(\mathrm{H}_{2} \mathrm{SO}_{4} / \mathrm{H}_{2} \mathrm{O}_{2}(70 / 30 \%(v / v))\right)$ for $1 \mathrm{~h}$, followed by $0.2 \mathrm{~N} \mathrm{NaOH}$ solution treatment and coated with aqueous $\mathrm{GO}$ solution $(1.0 \mathrm{mg} / \mathrm{ml})$. GO solution loaded cover glass was kept at $60{ }^{\circ} \mathrm{C}$ oven for overnight as loosen lids for covalent bonding between hydroxyl group on the glass surface and epoxy group of GO and slowly evaporated the solution.

\section{Cell culture and osteogenic differentiation}

C3H10T1/2, murine mesenchymal stem cells, were purchased from the Korean Cell Line Bank (KCLB) affiliated to Seoul National University Hospital (SNUH). C3H10T1/2 cells with passage number 26 were plated to the $18 \times 18 \mathrm{~mm} \mathrm{GO} /$ Glass slides at a density of $5 \times 10^{4}$ cells per slide and cultured with Dulbecco's Modified Eagle Medium (DMEM; GIBCO, USA). The medium was supplemented with $10 \%$ fetal bovine serum (FBS; GIBCO, USA) and 1\% penicillin/streptomycin (Pen/ Strep; GIBCO, USA). For osteogenic differentiation, cells were influenced by osteogenic differentiation substrate, as cultured in DMEM supplemented with $50 \mathrm{mg} / \mathrm{ml} \mathrm{L}$ ascorbic acid (Sigma-Aldrich, USA), 1\% Pen-Strep, 10\% FBS, $100 \mathrm{nM}$ dexamethasone (Sigma-Aldrich, USA), and 
$10 \mathrm{mM}$ glycerol-2-phosphate (Sigma-Aldrich, USA), for 14 days. Osteogenic differentiation medium was replaced for every day.

\section{Cell proliferation and viability analysis}

Cell proliferation was examined by the Alama Blue Assay Kit (Invitrogen, USA) according to the manufacturer's instructions. Cells were seeded onto the slides at a density of 5000 cells $/ \mathrm{cm}^{2}$ and incubated for $4 \mathrm{~h}$ with 1:10 Alama blue solution in the medium. After incubation, the Alama Blue solution containing medium is collected and the absorbance is measured using AT / Infinite M200 (TECAN, USA). Live / dead analysis was performed using live/dead viability kits (Invitrogen, USA) after $24 \mathrm{~h}$ of cell seeding on each slide. Twentyfour hours after seeding, the cells were incubated for 30 min with a live/dead solution containing calcein-AM and ethidium homodimer-1 (EthD-1). Images were then obtained using an LSM 720 confocal microscope (Zeiss).

\section{Morphological analysis}

After cells were cultured for 4 days with osteogenic differentiation medium $(\mathrm{OM})$, cells were fixed with $10 \%(\mathrm{v}$ / v) formalin and washed with PBS (3 times). Subsequently, permeabilized using $0.1 \%$ Triton $\mathrm{X}-100$ for $30 \mathrm{~min}$. Then, samples were stained with a mixture of 1 : 100 Phalloidin (Alexa Fluor 594, life technologies, USA) and 1: 500 vinculin (Abcam, USA) for $1 \mathrm{~h}$. After another $1 \mathrm{~h}$ of second antibody treatment, the cells were further stained with DAPI ( $\$$ 6-diamidino-2-phenylindole, Sigma-Aldrich) solution at a ratio of 1: 200 for $15 \mathrm{~min}$. The fluorescence image was obtained with a confocal microscope (ZEISS LSM 720).

\section{Real time-PCR}

RNA samples were obtained from each GO and glass slides $(n=4)$ containing cells with the Trizol method (Trizol ${ }^{\circ}$, Life Technology, USA). Total RNA concentration was measured with a NanoDrop spectrometer (ND2000, NanoDrop Technologies, USA). Each sample was normalized to $1000 \mathrm{ng}$ of total RNA and reverse transcribed into cDNA using the TOPscript ${ }^{\mathrm{Tx}}$ Reverse Transcriptase Kit (Enzynomics) according to the manufacturer's instructions. Real-time PCR was performed with ABI StepOnePlusTM real-time PCR system (Applied Biosystems, USA) using the SYBR Green PCR Master mix. Expressions of genes related with osteogenic differentiation such as GAPDH, Runx2, ALP, and OCN were analyzed. cDNA samples were loaded and the data were analyzed by the $-2^{\Delta \Delta C t}$ method. PCR primers sequence was as follows: GAPDH (forward: 5'-GTA TGA CTC CAC TCA CGG CAA A-3', reverse: 5'-CTA AGC AGT TGG TGG TGC AG-3'), RunX2 (forward: $5^{\prime}$-GGA CGA GGC AAG AGT TTC A-3', reverse: 5'-TGG TGC
AGA GTT CAG GCA G-3'), ALP (forward: 5'-GAA GTC CGT GGG CAT CGT-3', reverse: 5'-CAG TGC GGT TCC AGA CAT AG-3'), OCN (forward: 5'-AGC AGG AGG GCA ATA AGG-3', reverse: 5'-CGT AGA TGC GTT TGT AGG C-3').

\section{Calcium deposition analysis}

To analyze the calcium deposition, Alizarin Red S staining was performed. Cells were incubated with OM for 14 days, then the cells were fixed with $10 \%(\mathrm{v} / \mathrm{v})$ formalin and washed three times with PBS. To make the ARS solution, $20 \mathrm{mg}$ of Alizarin Red S powder (Sigma-Aldrich, USA) was dissolved in $1 \mathrm{ml}$ of distilled water and the $\mathrm{pH}$ was adjusted to $4.1 \sim 4.2$ with ammonium hydroxide $\left(\mathrm{NH}_{4} \mathrm{OH}\right)$. Fixed cells were stained with ARS solution for $20 \mathrm{~min}$ and washed 3 times with distilled water for $5 \mathrm{~min}$. For ARS quantification, $800 \mu \mathrm{l}$ of $10 \%$ ( $\mathrm{v} / \mathrm{v})$ acetic acid per well was added and incubated at room temperature for $30 \mathrm{~min}$. The cells were collected with a cell scraper, transferred to a $1.5 \mathrm{ml}$ tube, and $500 \mu \mathrm{l}$ of mineral oil was added. The samples were heated at $85{ }^{\circ} \mathrm{C}$ for $10 \mathrm{~min}$ and cooled with ice for $5 \mathrm{~min}$. The solution was then centrifuged at 20,000 G for $15 \mathrm{~min}$. After centrifugation, $500 \mu \mathrm{l}$ of supernatant was collected. Then, $200 \mu \mathrm{l}$ of $10 \%$ ammonium hydroxide was added to the supernatant to complete precipitation. To see the results, Absorbance values were measured with a spectrometer.

\section{Field emission scanning electron microscopy}

Cells seeded on GO / Glass slides were cultured in OM for 4 days, then fixed with $4 \%$ paraformaldehyde (Polysciences) for $15 \mathrm{~min}$, subsequently dehydrated with 70 $100 \%$ ethanol (Daejung Chemical) and treated with Hexamethyldisilazane (HMDS; Daejung Chemical) for $1 \mathrm{~h}$. The sample was visualized with a field emission scanning electron microscope (FE-SEM; JSM-6701F, JEOL) at $20 \mathrm{~mA}$ for $100 \mathrm{~s}$ after platinum coating.

\section{Western blotting}

Protein samples were collected with M-PER (Mammalian Protein Extraction Reagent) and protein expression was analyzed using $10 \%(w / v)$ SDS (sodium dodecyl sulfate) - polyacrylamide gel electrophoresis $(n=3$ per group) respectively. Protein was transferred to Immobilon-P membrane (Millipore Corp., USA) and blocked with $5 \%$ skim milk in $1 \times$ PBS-T (pH 7.5, 0.1\% Tween-20). Then, probed with primary antibodies against $\beta$-actin (\#6276, Abcam, USA) diluted in 1:5000 and vinculin (Abcam, USA) diluted in 1:1000 for overnight in a cold room with gentle agitation. The primary antibody probed proteins were incubated with the secondary antibody, anti-rabbit IgG horseradish-peroxidase conjugated, (\#7074, Cell Signaling, USA) in a 1:2000 
dilution for $1 \mathrm{~h}$ at room temperature. To visualize the protein expressions, the blots were developed by a chemiluminescence detection system (Amersham Bioscience, USA).

\section{Data analysis}

The quantitative data were expressed as the means \pm standard deviations. The statistical significances were analyzed by one-way analysis of variance (ANOVA) $\left({ }^{*} p<\right.$ $\left.0.05,{ }^{* * *} p<0.01\right)$.

\section{Results}

\section{Preparation and characterization of Graphene oxide coated slide}

Figure 1a represents the overall scheme for graphene oxide coated slide and osteogenic differentiation of C3H10T1/2 cells. Firstly, C3H10T1/2 cells were expanded with either chondrocyte-conditioned medium (CM) or control growth medium (GM) were utilized. Next these cells were cultured on either control glass slide or GO coated slide (Fig. 1a).

GO flakes were made by modified Hummers method [27], and GO flakes were coated on the $18 \times 18 \mathrm{~mm}$ glass slide. Covalent bonds were formed between hydroxyl group from glass surface treated with piranha solution and epoxy group of $\mathrm{GO}$ as $\mathrm{pH} 10$ water slowly evaporated at $60{ }^{\circ} \mathrm{C}$. For the GO coated slides, we observed that the surface of the graphene oxide coated slide formed a dark, thin and opaque layer compared to a glass slide (Fig. 1b). Moreover, the water contact angle was altered due to the GO coating (Fig. 1c). After GO coating, water contact angle was increased about $24^{\circ}$, indicating that the surface area of a GO coated slide was more hydrophobic than a glass slide.

\section{Cell proliferation, viability, and morphological change}

To observe the effect of chondrocyte-conditioned medium (CM) priming and GO coated slide, C3H10T1/ 2 cells were primed for 14 days with CM before seeding. Then, primed and non-primed cells were seeded at a same density on each glass slide or GO coated slide. After 4 days of seeding, cell surface area was altered by $\mathrm{CM}$ priming and $\mathrm{GO}$ coated slide. When compared to the non-primed cells, priming of $\mathrm{C} 3 \mathrm{H} 10 \mathrm{~T} 1 / 2$ cells resulted in 1.18 fold increased in cell size (Fig. 2a and b). The cell size of C3H10T1/2 cells on GO coated slide was $174.3 \mathrm{um}^{2}$ and primed C3H10T1/2 cells on graphene oxide coated slide was $189.2 \mathrm{um}^{2}$ indicating that the both CM expansion increased the cell coverage area.

SEM analysis showed the substrate-dependent adhesion efficiencies (Fig. 2a). On the GO coated slide, there were more cells attached, and the surface area of a single cell was larger than the surface area of a cell on a glass slide. GO substrate is highly capable of interacting with cells due to its hydrophilic property and high adsorption properties for proteins and soluble growth factors. These properties may have resulted in increased cell surface area and adhesion efficiencies.

For the cell viability analysis (Fig. 2c and d), we seeded primed and non-primed C3H10T1/2 cells on either glass slide and GO coated slide. After 1 day of seeding, we measured cellular proliferation and assayed for live/dead. Regardless of the substrate and cell types, all groups showed a similar level of viability (Fig. 2d). All groups showed more than $98 \%$ of survival rate indicating that

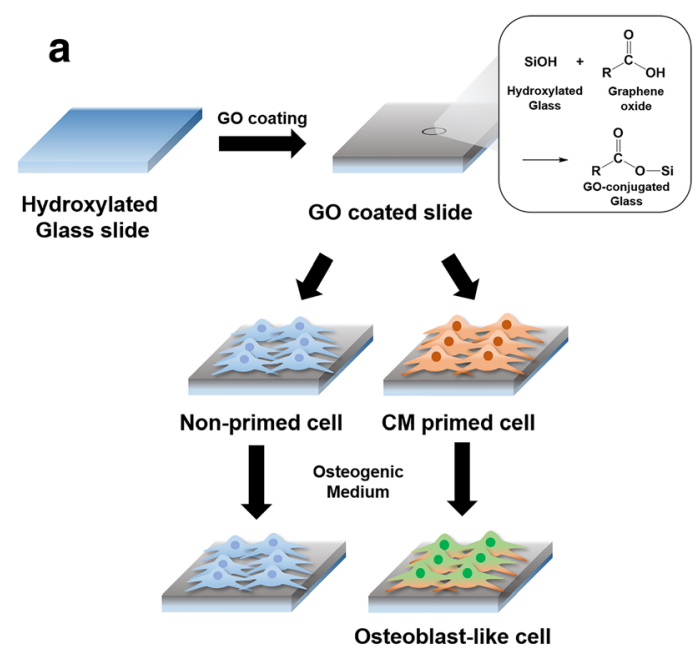

b
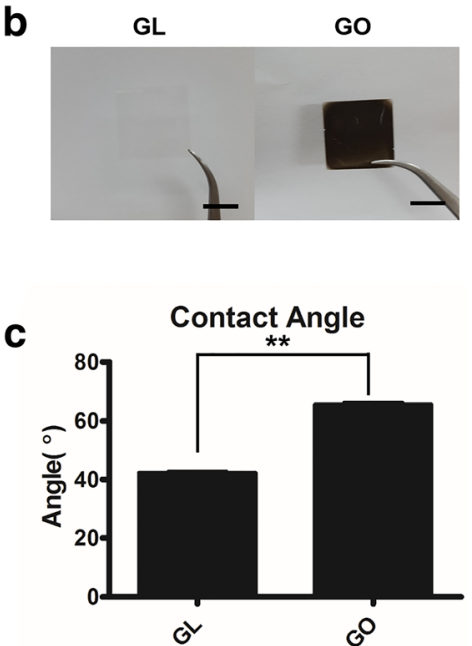

Fig. 1 a Overall scheme of designing in vitro study with GM/CM primed cell and glass/graphene oxide slide. $\mathbf{b}$ Image of normal glass slide (Control group) and Graphene oxide substrate coated slide, scale bar $=1 \mathrm{~cm}$. c Glass slide and graphene oxide substrate coated slide characterized with water contact angle 


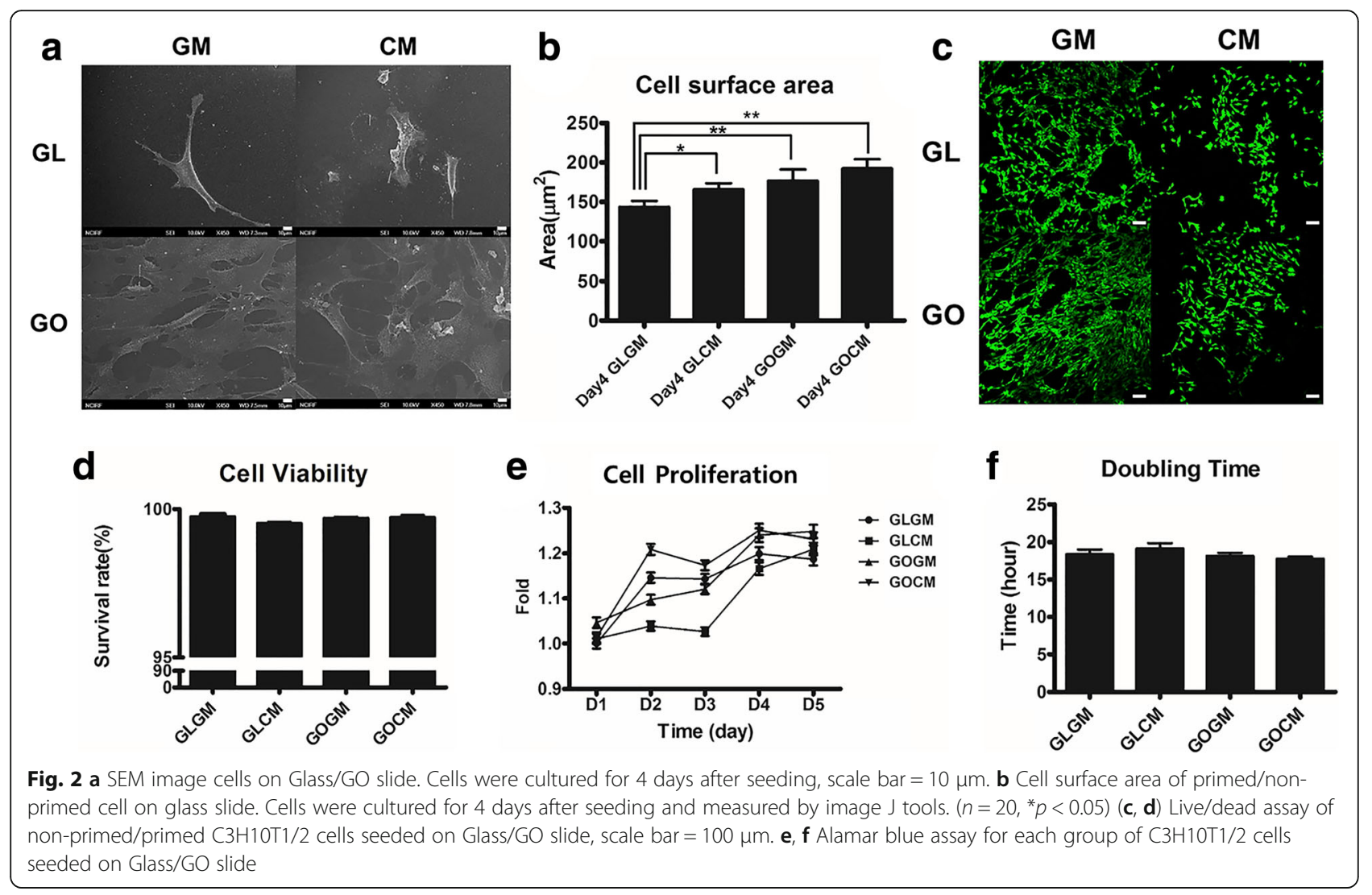

GO or CM did not invoke any significant cytotoxicity to cells.

CM primed cells on glass slide showed decreased proliferation rate compared to the non-primed group while CM primed cells on GO coated slide exhibited improved proliferation rate, as indicated by Alamar Blue assay (Fig. 2e). This suggests that the proliferation of primed cell is enhanced on GO coated slide. The cell doubling time of CM primed cells on GO coated slide showed a statistically significant difference compared with CM primed cells on a glass slide (Fig. 2f). Non-primed cells on glass slide showed a doubling time of $18.4 \mathrm{~h}$, primed cells on the glass slide have a doubling time of $19.2 \mathrm{~h}$, the longest doubling times among the groups. Nonprimed cells on GO coated slides have a doubling time of $18.1 \mathrm{~h}$ and primed cells on GO coated slides showed a doubling time of $17.6 \mathrm{~h}$, which was the shortest doubling time above all groups. In short, cell doubling times of primed cells were shortened on the GO coated slides for 0.916 times compared to non-primed cells on a glass slide. This result showed that the CM priming had a synergistic effect on the GO coated slides in terms of cellular proliferation. Furthermore, these results demonstrated that a synergistic effect of GO substrate and CM priming could result in morphological change, improved viability, and cellular proliferation.
Improved focal adhesion of CM primed cells on GO slide Previously, increased cell size coupled with increased focal adhesion kinase (FAK)has been showed to activate cytoskeletal tension via RhoA/Rock signaling pathways, which also enhances osteogenic commitment of stem cells [28]. We cultured primed or non-primed C3H10T1/2 cells on control glass slide of GO slide for 4 days and qualitatively analyzed the F-actin and vinculin by immunostaining (Fig. 3a). F-actin assembly is influenced by cellular tension, cell-ECM adhesion, and cellular surface area. CM primed cells exhibited especially stretched shape to various directions compared to non-primed cells for both on glass slide and GO coated slide (Fig. 3a). Furthermore, with the increased spread of F-actin in the CM primed groups, we showed that CM priming could play a great role to induce the change of cellular morphology and increase cell adhesion. To confirm the correlation between the effect of CM priming and GO slide on focal adhesion, we observed vinculin expression level of each group (Fig. 3b). Similar to previous data, vinculin expression was significantly raised in primed cells on GO coated slides group (GOCM), leading to improving focal adhesion of cells to slide, due to hydrophilicity and pi-bond conjugation of GO substrate. Previous studies showed that contacts with extracellular matrix (ECM) protein induce osteogenic differentiation 


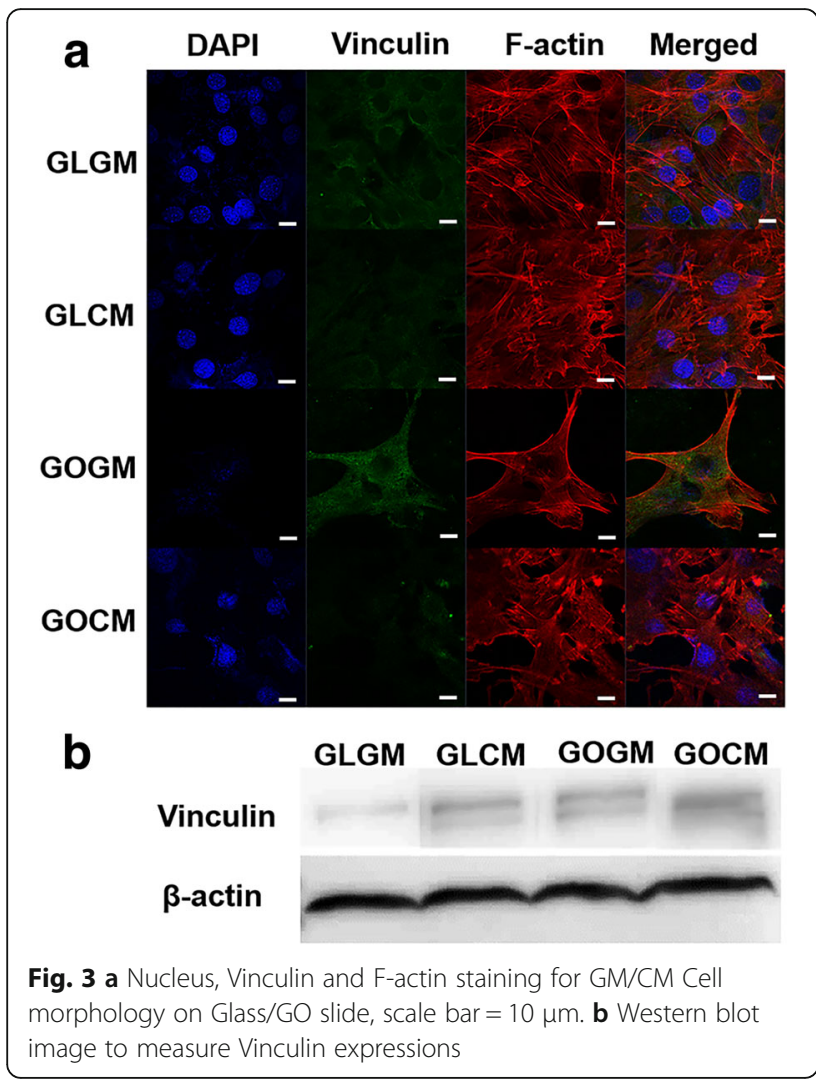

through a FAK signaling pathway and ERK-dependent pathway [29, 30]. Hence, increased expression of vinculin meant improved focal adhesion and contact with the extracellular matrix protein of cells. With these results, we hypothesized that CM priming and GO coated slide both induced the osteogenic differentiation of C3H10T1/2, along with other synergistic effects when they were used together. To show the cellular morphology and expression of focal adhesion protein increased osteogenic differentiation of $\mathrm{C} 3 \mathrm{H} 10 \mathrm{~T} 1 / 2$ cells, we investigated the effect of CM priming and GO coated slide on osteogenic responses by confirming osteogenic gene expressions and bone mineral deposition of each group.

\section{Osteogenic differentiation of $\mathrm{C} 3 \mathrm{H} 10 \mathrm{~T} 1 / 2$ cells}

We cultured CM primed and non-primed C3H10T1/2 cells on each group of slides in the osteogenic medium for 14 days. Osteogenic medium contained ascorbic-2phosphate, dexamethasone and $\beta$-glycerophosphate, which are required for osteogenic differentiation [31, 32]. After culturing cells, osteogenic gene expressions were analyzed by real-time PCR. Compared to those of control group (GLGM), CM primed cells on GO coated slide showed a substantially enhanced osteogenic gene expressions including osteocalcin (OCN, noncollagenous protein found in bone), alkaline phosphatase (ALP, protein promoting osteoblastic activity), runt- related transcription factor 2 (Runx2, early osteogenic gene marker), bone morphogenetic protein 2 (BMP2, essential protein in the development of bone and cartilage), and BMP receptor (BMPR1A) (Fig. 4a). Upregulation of osteogenic gene expression in CM primed cells on glass slide (GLCM) group and non-primed cells on GO slide (GOGM) was observed, yet primed cells on GO coated slides group (GOCM) were in a higher range of expression.

To determine whether $\mathrm{C} 3 \mathrm{H} 10 \mathrm{~T} 1 / 2$ cells differentiated into osteoblast cells, we measured the calcium contents from differentiated cells by Alizarin Red S staining (Fig. $4 \mathrm{~b}$ and $\mathrm{c}$ ). On the glass slide, the intensity of ARS stained cells (Red) was more distinguished on CM primed cell. It demonstrated that CM priming could augment the content of calcium deposition. The same phenomenon was observed on the GO slide as well. Furthermore, primed cells on the GO slide presented the greatest calcium deposition rate among all groups. We facilitated ARS quantification to measure the calcium deposition level quantitatively. In agreement with osteogenic gene expression analysis by real-time PCR, cells under the condition of CM or GO slide could deposit more calcium contents than either non-primed cells or cells on glass side. The highest amount of calcium detected in primed cells on GO coated slides group (GOCM) further supported that CM and GO reinforced the synergistic effect in osteogenesis.

\section{Discussion}

Previous studies showed that GO substrate can enhance the osteogenic commitment of stem cells [16]. GO substrate usually functions as cell adhesive platform improving cell adhesion and cell-protein interactions [8, 9]. Furthermore, in a separate study, bovine chondrocyte conditioned medium (CM) priming has been shown to enhance the osteogenic differentiation of mouse or human mesenchymal stem cells $[33,34]$. Conditioned medium treating also played a role by improving both chondrogenic and osteogenic responsibility of mesenchymal stem cells through the interaction of cells with the secreted factors from bovine chondrocytes [19, 30].

In this study, we investigated the effect of conditioned medium priming and GO coated slide on osteogenic differentiation of $\mathrm{C} 3 \mathrm{H} 10 \mathrm{~T} 1 / 2$ cells, and demonstrated that the synergistic effect of GO coated slide and CM priming could facilitate osteogenesis of C3H10T1/2 (murine mesenchymal stem cells). GO coated surface had increased interaction of extracellular matrix and cells [35]. From our experiment, however, we saw a subtle increase in contact angle. This is due to the carbon components of GO. GO is basically composed of carbon atoms. Usually, long carbon chain shows hydrophobic characters. However, GO coated slide shows hydrophilic features 


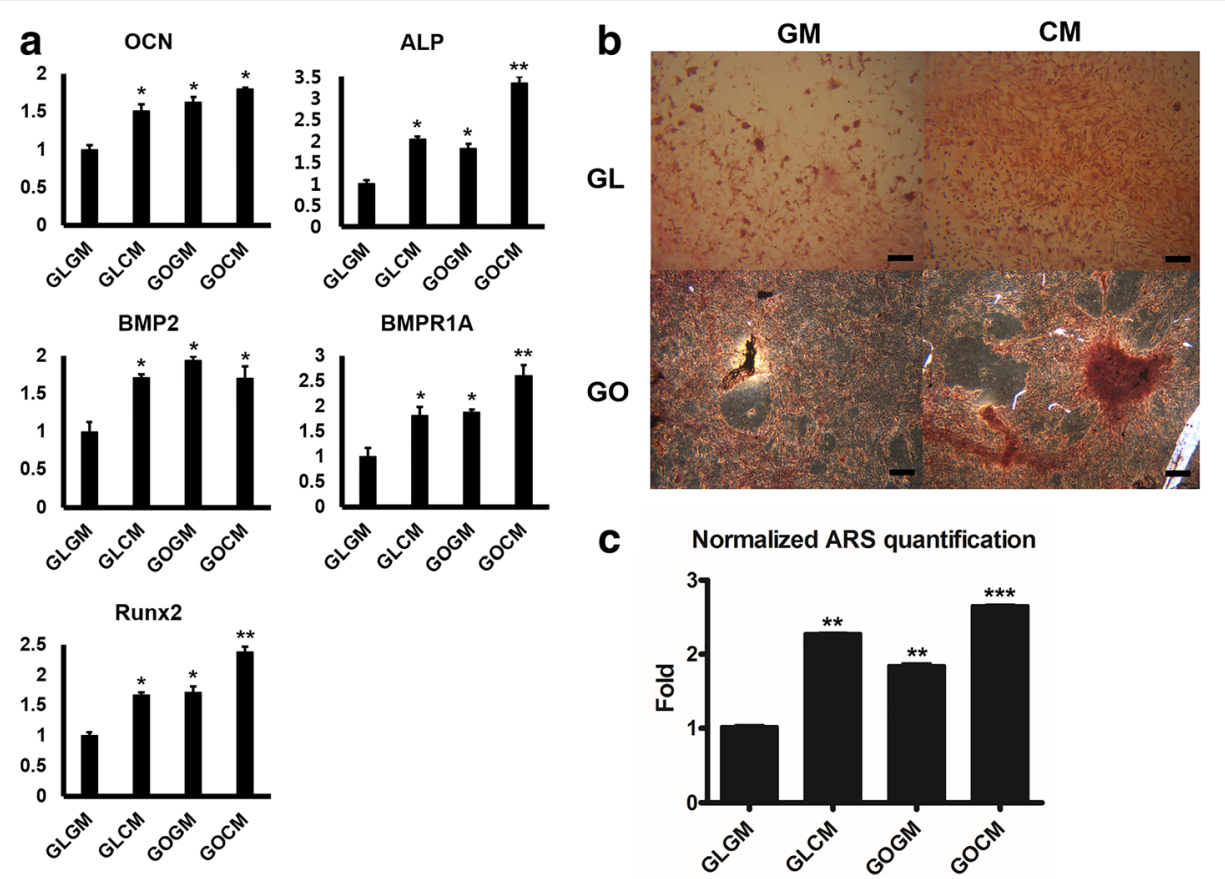

Fig. 4 a Osteogenic marker expression of the non-primed/primed C3H10T1/2 cells seeded on Glass/GO slide. Real-time PCR was performed after 14 days of osteogenic medium culture on each groups $\left({ }^{*} p<0.05,{ }^{* *} p<0.01\right)$. b Alizarin red staining of non-primed/primed cell on glass slide. Alizarin red staining was performed after 14 days of osteogenic medium culture. Scale bar $=100 \mu \mathrm{m}$. c ARS staining quantification of non-primed/primed cell on glass/GO slide. Absorbance at $405 \mathrm{~nm}$, normalized by non-primed cell on glass slide (GLGM). The primed cell (CM) has more calcium deposition on it $\left({ }^{* *} p<0.01,{ }^{* * *} p<0.001\right)$

because of its pi bond conjugation and hydrophilic functional groups like $-\mathrm{OH}$ and $-\mathrm{COOH}$ [15], which may affect the focal adhesion of cell and cell proliferation. Furthermore, the interaction of cells with hydrophilic growth factors like TGF-B groups can be influenced by GO coating. As a result, these properties of GO substrate support that the GO coated surface are highly capable of interacting with cells due its high reactivity to the other proteins and growth factors.

Firstly, we observed that cell surface area from the GO coated slide groups was larger than that from the glass slide groups. Furthermore, the configuration of cell and adhesion rate was different. SEM image showed that there was a significant difference in the cell attachment rate between glass slide group and GO coated slide group, even though both groups had the same amount of days of cell culture with equal cell density. On the GO coated slide, attached cells were more apparent. GO coated slide presented enhanced cell interaction because of its hydrophilic property and these properties also affected the cell morphology such as increased cell surface area and cell adhesion rate.

In addition, CM priming also increased cell surface area. In this experiment, we used $\mathrm{CM}$ which contained chondrocyte secreted factors to prime C3H10T1/2 cells. Primed cells on GO slide showed larger surface area than non-primed groups. Among those groups, CM primed cells on GO coated slide showed most stretched shapes to various directions and higher cell adhesion rate, which indicates higher potential and efficiency to be differentiated in direction of osteogenesis [28, 36]. In order to directly observe the cellular response of $\mathrm{CM}$ priming and GO substrate, primed C3H10T1/2 cells on GO slide with growth medium (i.e., without osteogenic factors) provide sufficient evidence for cellular commitment. However, our previous study has demonstrated the primed $\mathrm{C} 3 \mathrm{H} 10 \mathrm{~T} 1 / 2$ cells cultured with growth medium resulted in stimulated chondrogenic response (i.e., not osteogenic response) [37]. Since our intention in this study was to observe the osteogenic response, we have utilized the osteogenic differentiation medium.

In terms of cell viability and proliferation of each group, primed and non-primed cells on both glass and GO slides acquired more than $98 \%$ of survival rate, as shown in Fig. 2d. This demonstrates that GO coating or $\mathrm{CM}$ does not have cytotoxicity. As a result, primed cells on glass slide exhibited the longest doubling time among all groups. However, primed cells on GO coated slide showed the shortest doubling time. This result indicates that CM priming facilitates cell proliferation of cells with GO coated slide, not only through conditioned medium's effect, but also synergistic effect with GO coated slide. As described on Fig. 2a, the cellular morphology of conditioned medium primed cells was especially stretched 
to various directions compared to non-primed cells. These morphological change on CM primed cells allows the cells to be effectively influenced through contacts with substrate. Moreover, hydrophilic properties of GO can increase the interaction of bovine chondrocyte secreted factors with the cells, which have up-regulating effect on osteogenic differentiation of mesenchymal stem cells $[38,39]$.

With increased cell surface area, CM primed cell showed stretched F-actin in various directions, and vinculin expression level showed enhancement of focal adhesion for primed cells. Also, increased cell surface area and stretched F-actin on GO slide due to the hydrophilic characters of GO indicates that the effect of focal adhesion protein and extracellular matrix interaction with cells were increased. Therefore, we can speculate that CM primed cells and GO coated slide could have synergistic effects because chondrocyte secreted factors, which had the influence to primed cells, had improved focal adhesion and enhanced the effect of GO substrate on cells. Moreover, it is known that mechanical stimulus on stem cell has a significant effect on its differentiation ability. As the stimulus level increases, the morphology of the cell stretches to various directions and the cell surface area is increases. Those morphological changes shows to have great influence on osteogenic differentiation of the mesenchymal stem cell [28]. In this regard, we demonstrated that the spread of F-Actin, the increased cell surface area of primed cells and, cell growth on GO coated slides enhanced the osteogenic differentiation of cells. In addition, the results of confirming the expression of vinculin, protein related with focal adhesion, through Western blotting had same tendency. The expression level of vinculin was highest at CM primed cells seeded on GO coated slides group.

In this study, furthermore, osteogenic gene marker expressions and ARS staining results supported that the CM priming also to enhance osteogenic responses and calcium deposition. Gene expression level of osteogenic gene markers such as OCN, ALP, Runx2, BMP2, and BMPR1A were upregulated via $\mathrm{CM}$ priming and $\mathrm{GO}$ substrate culturing. Simlar to the study by Lee and colleagues, primed cells on GO coated slide showed enhanced osteogenic responses and calcium deposition [40].

\section{Conclusion}

CM priming and GO coated slide affected proliferation, morphological change, and focal adhesions of the C3H10T1/2 cells. CM primed cell with GO slide showed substantially increased osteogenic responses. As a result, CM primed cells seeded on GO slides showed morphological change like increased cell surface and stretched to various direction. In addition, cell proliferation also increased as GO slide was applied. Focal adhesion of mesenchymal stem cells was enhanced as the result is shown at western blot image. This can induce osteogenic differentiation effectively. With the CM priming and GO coated slide, the gene expression level of the osteogenic markers like OCN, ALP, Runx2, BMP2 and BMP2R1A and calcium deposition was upregulated. In short, $C M$ primed cell on GO coated slide showed considerably enhanced osteogenic response compared to any other groups in the experiment. With these results, we could see the synergistic effects of GO and conditioning medium priming. Those synergistic effects of CM priming with GO coating enhanced osteogenic commitment of C3H10T1/2 cells, mesenchymal-like stem cells, and it is possible to utilize these synergistic effects to increase the rate of differentiation of MSCs to osteoblast. Furthermore, CM priming with GO substrate can take part in a solution to excel bone rehabilitation or other therapeutic application such as bone graft therapeutic and, perhaps, tissue engineering as a whole.

\section{Abbreviations \\ A2P: Ascorbic 2-phosphate; ALP: Alkaline phosphatase; BMP2: Bone morphogenetic protein 2; BMPR1A: Bone morphogenetic protein receptor 1A; C3H: C3H10T1/2 cells; CM: Chondrocyte-conditioned medium; COL I: Collagen type I; ECM: Extracellular matrix; FAK: Focal adhesion kinase; GL : Glass slide; GLCM: Primed cells on glass slide group; GLGM: Non-primed cells on glass slide group; GM: Growth medium; GO: Graphene oxide; GOCM: Primed cells on graphene oxide slide group; GOGM: Non-primed cells on graphene oxide slide group; OCN: Osteocalcin; RUNX2: Runt-related transcription factor 2; TGF-B: Transforming growth factor- $\beta$}

\section{Funding}

This research was supported by the National Research Foundation of Korea (NRF) funded by the Ministry of Science, ICT \& Future Planning (NRF-2016R1E1A1A01943393, NRF-2017M3A9C6029699).

\section{Availability of data and materials}

Not applicable.

\section{Author's contributions}

The research was designed and coordinated by J.K and N.S.H. The scaffold fabrication and analysis were performed by J.K, H.D.K, J.Y. Cell and molecular analysis was performed by J.K, H.D.K, E.L and J.P. H.D.K, J.K, E.K, S.S.L, Y.L and N.S.H wrote, revised and improved the final manuscript. All authors read and approved the final manuscript.

Ethics approval and consent to participate Not applicable.

Consent for publication

Not applicable.

Competing interests

The authors declare that they have no competing interests.

\section{Publisher's Note}

Springer Nature remains neutral with regard to jurisdictional claims in published maps and institutional affiliations.

\section{Author details}

${ }^{1}$ School of Chemical and Biological Engineering, Institute of Chemical Processes, Seoul National University, 1 Gwanak-ro, Gwanak-gu, Seoul 151-742, Republic of Korea. ${ }^{2}$ Interdisciplinary Program in Bioengineering, Seoul National University, Seoul 152-742, Republic of Korea. ${ }^{3} \mathrm{~N}-\mathrm{Bio} / \mathrm{BioMAX}$ Institute, Seoul National University, Seoul 152-742, Republic of Korea. 


\section{Received: 23 November 2017 Accepted: 12 December 2017}

\section{Published online: 02 January 2018}

\section{References}

1. Bottcher-Haberzeth S, Biedermann T, Reichmann E. Tissue engineering of skin. Burns. 2010;36:450-60.

2. Clark RA, Ghosh K, Tonnesen MG. Tissue engineering for cutaneous wounds. J Invest Dermatol. 2007;127:1018-29.

3. Horch RE, Kopp J, Kneser U, Beier J, Bach AD. Tissue engineering of cultured skin substitutes. J Cell Mol Med. 2005;9:592-608.

4. Kim HD, Amirthalingam S, Kim SL, Lee SS, Rangasamy J, Hwang NS. Biomimetic materials and fabrication approaches for bone tissue engineering. Adv Healthc Mater. 2017;6:23.

5. Pittenger MF, Mackay AM, Beck SC, Jaiswal RK, Douglas R, Mosca JD, Moorman MA, Simonetti DW, Craig S, Marshak DR. Multilineage potential of adult human mesenchymal stem cells. Science. 1999;284:143-7.

6. Caplan Al. Mesenchymal stem cells. J Orthop Res. 1991;9:641-50.

7. Karageorgiou V, Kaplan D. Porosity of 3D biomaterial scaffolds and osteogenesis. Biomaterials. 2005;26:5474-91.

8. Li WJ, Tuli R, Huang X, Laquerriere P, Tuan RS. Multilineage differentiation of human mesenchymal stem cells in a three-dimensional nanofibrous scaffold. Biomaterials. 2005;26:5158-66.

9. Vinatier C, Bouffi C, Merceron C, Gordeladze J, Brondello JM, Jorgensen C, Weiss P, Guicheux J, Noel D. Cartilage tissue engineering: towards a biomaterial-assisted mesenchymal stem cell therapy. Curr Stem Cell Res Ther. 2009:4:318-29.

10. Kim HD, Lee EA, An YH, Kim SL, Lee SS, Yu SJ, Jang HL, Nam KT, Im SG, Hwang NS. Chondroitin sulfate-based biomineralizing surface Hydrogels for bone tissue engineering. ACS Appl Mater Interfaces. 2017;9:21639-50.

11. Dawson E, Mapili G, Erickson K, Taqvi S, Roy K. Biomaterials for stem cell differentiation. Adv Drug Deliv Rev. 2008;60:215-28.

12. Cheng H, Byrska-Bishop M, Zhang CT, Kastrup CJ, Hwang NS, Tai AK, Lee WW, Xu X, Nahrendorf M, Langer R, Anderson DG. Stem cell membrane engineering for cell rolling using peptide conjugation and tuning of cellselectin interaction kinetics. Biomaterials. 2012;33:5004-12.

13. Dalby MJ, McCloy D, Robertson M, Agheli H, Sutherland D, Affrossman S, Oreffo RO. Osteoprogenitor response to semi-ordered and random nanotopographies. Biomaterials. 2006;27:2980-7.

14. Shin YC, Song SJ, Hong SW, Jeong SJ, Chrzanowski W, Lee JC, Han DW. Multifaceted biomedical applications of functional Graphene Nanomaterials to coated substrates, patterned arrays and hybrid scaffolds. Nanomaterials (Basel). 2017;7(11):369.

15. Shi XT, Chang HX, Chen S, Lai C, Khademhosseini A, Wu HK. Regulating cellular behavior on few-layer reduced Graphene oxide films with wellcontrolled reduction states. Adv Funct Mater. 2012;22:751-9.

16. Kim HD, Kim J, Koh RH, Shim J, Lee JC, Kim TI, Hwang NS. Enhanced Osteogenic commitment of human Mesenchymal stem cells on polyethylene glycol-based Cryogel with Graphene oxide substrate. Acs Biomaterials Science \& Engineering. 2017;3:2470-9.

17. Zhang Y, Wu CY, Guo SW, Zhang JY. Interactions of graphene and graphene oxide with proteins and peptides. Nanotechnol Rev. 2013;2:27-45.

18. Ding ZJ, Ma HW, Chen YY. Interaction of graphene oxide with human serum albumin and its mechanism. RSC Adv. 2014;4:55290-5.

19. Luo $Y$, Shen H, Fang Y, Cao Y, Huang J, Zhang M, Dai J, Shi X, Zhang Z. Enhanced proliferation and osteogenic differentiation of mesenchymal stem cells on graphene oxide-incorporated electrospun poly(lactic-co-glycolic acid) nanofibrous mats. ACS Appl Mater Interfaces. 2015;7:6331-9.

20. Nair M, Nancy D, Krishnan AG, Anjusree GS, Vadukumpully S, Nair SV. Graphene oxide nanoflakes incorporated gelatin-hydroxyapatite scaffolds enhance osteogenic differentiation of human mesenchymal stem cells. Nanotechnology. 2015;26:161001.

21. Nayak TR, Andersen H, Makam VS, Khaw C, Bae S, Xu X, Ee PL, Ahn JH, Hong BH, Pastorin G, Ozyilmaz B. Graphene for controlled and accelerated osteogenic differentiation of human mesenchymal stem cells. ACS Nano. 2011:5:4670-8.

22. Guilak F, Cohen DM, Estes BT, Gimble JM, Liedtke W, Chen CS. Control of stem cell fate by physical interactions with the extracellular matrix. Cell Stem Cell. 2009:5:17-26.

23. Kratchmarova I, Blagoev B, Haack-Sorensen M, Kassem M, Mann M. Mechanism of divergent growth factor effects in mesenchymal stem cell differentiation. Science. 2005;308:1472-7.
24. Gerstenfeld LC, Cruceta J, Shea CM, Sampath K, Barnes GL, Einhorn TA. Chondrocytes provide morphogenic signals that selectively induce osteogenic differentiation of mesenchymal stem cells. J Bone Miner Res. 2002:17:221-30

25. Ro H, Park J, Yang K, Kim J, Yim HG, Jung G, Lee H, Cho SW, Hwang NS. Osteogenic priming of mesenchymal stem cells by chondrocyteconditioned factors and mineralized matrix. Cell Tissue Res. 2015; 362(1):115-26.

26. Koh RH, Jin Y, Kang BJ, Hwang NS. Chondrogenically primed tonsil-derived mesenchymal stem cells encapsulated in riboflavin-induced photocrosslinking collagen-hyaluronic acid hydrogel for meniscus tissue repairs. Acta Biomater. 2017;53:318-28.

27. Shahriary L, Athawale AA. Graphene oxide synthesized by using modified hummers approach. Int J Renew Energy Environ Eng. 2014;2:58-63.

28. Wang YK, Yu X, Cohen DM, Wozniak MA, Yang MT, Gao L, Eyckmans J, Chen CS. Bone morphogenetic protein-2-induced signaling and osteogenesis is regulated by cell shape, RhoA/ROCK, and cytoskeletal tension. Stem Cells Dev. 2012;21:1176-86.

29. Tong L, Buchman SR, Ignelzi MA Jr, Rhee S, Goldstein SA. Focal adhesion kinase expression during mandibular distraction osteogenesis: evidence for mechanotransduction. Plast Reconstr Surg. 2003;111:21122. discussion 223-214

30. Salasznyk RM, Klees RF, Williams WA, Boskey A, Plopper GE. Focal adhesion kinase signaling pathways regulate the osteogenic differentiation of human mesenchymal stem cells. Exp Cell Res. 2007;313:22-37.

31. Jaiswal N, Haynesworth SE, Caplan Al, Bruder SP. Osteogenic differentiation of purified, culture-expanded human mesenchymal stem cells in vitro. J Cell Biochem. 1997;64:295-312.

32. Yuasa M, Yamada T, Taniyama T, Masaoka T, Xuetao W, Yoshii T, Horie M, Yasuda H, Uemura T, Okawa A, Sotome S. Dexamethasone enhances osteogenic differentiation of bone marrow- and muscle-derived stromal cells and augments ectopic bone formation induced by bone morphogenetic protein-2. PLoS One. 2015;10:e0116462.

33. Jang HL, Jin K, Lee J, Kim Y, Nahm SH, Hong KS, Nam KT. Revisiting whitlockite, the second most abundant biomineral in bone: nanocrystal synthesis in physiologically relevant conditions and biocompatibility evaluation. ACS Nano. 2014;8:634-41.

34. Hwang NS, Varghese S, Lee HJ, Zhang Z, Elisseeff J: Biomaterials directed in vivo osteogenic differentiation of mesenchymal cells derived from human embryonic stem cells. Tissue Eng Part A 2013, 19:1723.

35. Tatavarty R, Ding H, Lu G, Taylor RJ, Bi X. Synergistic acceleration in the osteogenesis of human mesenchymal stem cells by graphene oxidecalcium phosphate nanocomposites. Chem Commun (Camb). 2014;50: 8484-7.

36. Yang F, Williams CG, Wang D-A, Lee H, Manson PN, Elisseeff J. The effect of incorporating RGD adhesive peptide in polyethylene glycol diacrylate hydrogel on osteogenesis of bone marrow stromal cells. Biomaterials. 2005; 26:5991-8.

37. Ro H, Park J, Yang K, Kim J, Yim HG, Jung G, Lee H, Cho SW, Hwang NS. Osteogenic priming of mesenchymal stem cells by chondrocyte-conditioned factors and mineralized matrix. Cell Tissue Res. 2015;362:115-26.

38. Kanczler J, Oreffo R. Osteogenesis and angiogenesis: the potential for engineering bone. Eur Cell Mater. 2008;15:100-14

39. Hwang NS, Varghese S, Puleo C, Zhang Z, Elisseeff J. Morphogenetic signals from chondrocytes promote chondrogenic and osteogenic differentiation of mesenchymal stem cells. J Cell Physiol. 2007;212:281-4.

40. Lee WC, Lim CH, Shi H, Tang LA, Wang Y, Lim CT, Loh KP. Origin of enhanced stem cell growth and differentiation on graphene and graphene oxide. ACS Nano. 2011;5:7334-41. 